\title{
Endoscopia en pacientes antiagregados
}

\section{¿QUÉ ES UN ANTIAGREGANTE?}

Un antiagregante es un fármaco que evita que las plaquetas, unas células que tenemos en la sangre, se agreguen, es decir, se unan entre sí para formar trombos sanguíneos. Se utilizan para evitar la trombosis en situaciones de riesgo como sería tras la colocación de prótesis o stents en las arterias del corazón. Además se usan para prevenir trombos en pacientes con diabetes o hipertensión y tras trombosis cerebrales entre otras indicaciones.

\section{¿QUÉ ANTIAGREGANTES EXISTEN?}

El más conocido y utilizado es la aspirina o ácido acetil salicílico (AAS ${ }^{\circledR}$, Acido Acetilsal Bayer $^{\circledR}$, Adiro ${ }^{\circledR}$, Bioplak $^{\circledR}$, Therasacard ${ }^{\circledast}$, Tromalyt ${ }^{\circledR}$ ). También se utilizan con frecuencia el clopidogrel (Iscover $^{\circledR}$, Plavix $^{\circledast}$ ), el trifusal (Disgren ${ }^{\circledR}$ ), la ticlopidina (Tiklid ${ }^{\circledR}$, Ticlodone ${ }^{\circledR}$, Ticlopidina $\mathrm{EFG}^{\circledast}$ ), y ya con menos frecuencia el dipiridamol (Per$\operatorname{santin}^{\circledR}$ ) y el tirofiban $\left(\right.$ Aggrastat $\left.^{\circledast}\right)$.

\section{¿SE PUEDE HACER UNA GASTROSCOPIA O UNA COLO- NOSCOPIA EN PACIENTES QUE TOMEN ANTIAGRE- GANTES?}

Sí. Con toda seguridad e incluso es perfectamente posible tomar biopsias con una pinza sin que se haya demostrado un aumento del riesgo de sangrado.

\section{¿SE PUEDEN HACER TÉCNICAS MÁS COMPLEJAS, COMO QUITAR PÓLIPOS, EN PACIENTES QUE TOMEN ANTIAGREGANTES?}

Es posible realizar muchas técnicas endoscópicas en pacientes que toman antiagregantes, como las polipectomías simples. Sin embargo existen otras que se consideran de alto riesgo de sangrado, como la polipectomía de pólipos complejos y técnicas de cirugía endoscópica. En estas situaciones se deben retirar los antiagregantes si es posible, si bien no hay estudios concluyentes acerca de la actitud a seguir.

\section{¿CUÁL ES EL RIESGO QUE TENGO SI DEJO LOS ANTIA- GREGANTES ANTES DE HACERME UNA ENDOSCOPIA DIGESTIVA?}

El principal riesgo es la trombosis, habitualmente, en las arterias cerebrales. Este riesgo es mayor en los pacientes a los que se ha puesto un stent en las arterias coronarias. En menor cuantía existe este riesgo en pacientes que han sufrido previamente trombosis cere- brales. El riesgo es mínimo cuando se utilizan como prevención primaria en pacientes diabéticos o hipertensos.

PARA EVITAR EL SANGRADO DIGESTIVO, ¿CUÁNTOTIEMPO ANTES DE UNA PRUEBA TENGO QUE DEJAR LOS ANTIAGREGANTES? ¿Y CUÁNDO DEBO REINICIARLOS?

Cada antiagregante tiene un tiempo determinado en el que ejerce su efecto. De forma general, con 7 días se considera que cede el efecto antiagregante de la mayor parte de ellos, si bien con la ticlopidina deben pasar 10 días y el dipiridamol y el tirofibran sólo necesitan 1 día.

En cuanto al reinicio del fármaco si se ha decidido previamente su retirada depende del procedimiento endoscópico que se haya realizado y la potencialidad sangrante del mismo.

\section{SI TOMO 2 ANTIAGREGANTES DISTINTOS, ¿CUÁL PUE- DO DEJAR?}

Los pacientes portadores de stents en las arterias del corazón suelen necesitar doble angiagregación (aspirina o derivados y clopidogrel) durante un periodo de tiempo variable entre 1 mes y 18 meses. En estos casos, y si es esencial realizar un procedimiento endoscópico de riesgo, se puede retirar el clopidogrel manteniendo la aspirina.

\section{¿EXISTE ALGUNA ALTERNATIVA A LOS ANTIAGRE- GANTES PARA DISMINUIR EL RIESGO DE TROMBOSIS SIN AUMENTAR EL RIESGO DE SANGRADO?}

Sí. En casos de cierto riesgo de trombosis y cuando el procedimiento endoscópico se considera inaplazable se puede sustituir el antiagregante por heparina de bajo peso molecular. Esta práctica es habitual y ofrece una cierta protección añadida, siendo importante ajustar dosis y plazos según protocolos aplicados a cada enfermo.

En todo caso, cualquiera de estas cuestiones siempre deben manejarse de forma individualizada y esto debe hacerse por parte de su médico, atendiendo criterios de riesgo de trombosis y sangrado frente al beneficio de las técnicas endoscópicas. Por ello a veces es conveniente retrasar las mismas hasta conseguir un momento más apropiado por su seguridad.

Fernando Alberca de las Parras

Servicio de Aparato Digestivo. Hospital Virgen de Arrixaca. Murcia 